\title{
Why Chronic Obstructive Pulmonary Disease Patients Get So Short of Breath with Limited Activity
}

\author{
Nicola Scichilone ${ }^{a}$ Arthur F. Gelb ${ }^{b}$

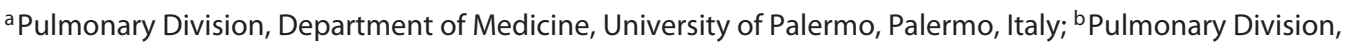 \\ Department of Medicine, Lakewood Regional Medical Center, Lakewood, Calif., USA
}

The international GOLD guidelines on the management of chronic obstructive pulmonary diseases (COPD) recommend that both serial lung function studies including spirometry and oxygen saturation at rest and during physical activity and overall health status should be regularly assessed to properly manage the disease [1]. The main subjective complaint of COPD patients with mild but especially moderate-to-severe expiratory airflow limitation is dyspnea associated with impaired exercise tolerance and progressive limitation of their activities of daily living (ADL) [1]. It is now accepted that dyspnea is in part related to the perception of difficulty in breathing through narrowed or destroyed small airways $<2 \mathrm{~mm}$ ID due to increased peripheral intrinsic airway obstruction and variable loss of lung elastic recoil due to superimposed emphysema. Dyspnea is also related to resting and exercise-induced dynamic hyperinflation (DH), which poses an elastic load on the respiratory system with resultant inspiratory muscle weakness and eventually fatigue. In this setting, the study by Lahaije et al. [2], published in this issue of Respiration, highlights the importance of evaluating $\mathrm{DH}$ in a real-life setting during $\mathrm{ADL}$, as well as during cardiopulmonary exercise testing (CPET) and metronome-paced tachypnea (MPT). We have previously demonstrated the equivalence despite the simplicity of MPT versus CPET as a surrogate to detect $\mathrm{DH}$ in COPD patients, by measuring the decrease in inspiratory capacity to reflect the increase in end-expiratory lung volume [3]. Lahaije et al. [2] have investigated whether $\mathrm{DH}$ as measured in the laboratory settings (CPET and MPT) reflects DH that is associated with dyspnea-limiting ADL. The authors conclude that both CPET and MPT can serve as a screening tool to identify patients who are susceptible to develop DH during ADL. In practice, MPT is simpler to obtain and is an inexpensive surrogate. However, sensitivity of MPT may not be optimal. When DH does not occur during CPET, it is unlikely to occur during ADL. The study also surprisingly demonstrated that one third of the study subjects with mild COPD experienced DH during ADL. However, the prognostic value of this observation has yet to be established. Results in the present study extend previously published somewhat similar observations by the same authors $[4,5]$.

Physicians should be aware that $\mathrm{DH}$ can occur in most symptomatic patients with COPD and may contribute to the problem of breathlessness during ADL. Revealing changes in the impact of COPD on a patient's life can be more useful than demonstrating improvements in conventional lung function. Therapeutic interventions to re-

\section{KARGER}

E-Mail karger@karger.com

www.karger.com/res
(C) 2013 S. Karger AG, Basel

0025-7931/13/0863-0177\$38.00/0
Nicola Scichilone, MD

Pulmonary Division, Department of Medicine

University of Palermo, Via Trabucco 180

IT-90146 Palermo (Italy)

E-Mail nicola.scichilone@unipa.it 
lieve dyspnea and reduce $\mathrm{DH}$ during $\mathrm{ADL}$ remain important goals $[6,7]$. However, we recently demonstrated that tiotropium was unable to reduce $\mathrm{DH}$ during MPT in moderately severe COPD patients despite significant bronchodilation in $\mathrm{FEV}_{1}$ (liters) and a decrease in func- tional residual capacity/total lung capacity at trough compared to placebo and despite the varying extent of lung CT-scored emphysema [8]. Unfortunately, this therapeutic conundrum remains a challenge to physicians and a burden to COPD patients with DH during ADL.

\section{References}

1 Vestbo J, Hurd SS, Agustí AG, Jones PW, Vogelmeier C, Anzueto A, et al: Global strategy for the diagnosis, management, and prevention of chronic obstructive pulmonary disease: GOLD executive summary. Am J Respir Crit Care Med 2013;187:347-365.

$>2$ Lahaije A, van Helvoort H, Dekhuijzen R, Heijdra Y: Can COPD patients who hyperinflate during daily life activities be identified by laboratory tests? Respiration 2013;86:237242 .
Gelb AF, Gutierrez CA, Weisman IM, Newsom R, Taylor CF, Zamel N: Simplified detection of dynamic hyperinflation. Chest 2004; 126:1855-1860.

4 Hannink JD, van Helvoort HA, Dekhuijzen PN, Heijdra YF: Dynamic hyperinflation during daily activities: does COPD global initiative for chronic obstructive lung disease stage matter? Chest 2010;137:1116-1121.

5 Lahaije A, van Helvoort H, Dekhuijzen P, Heijdra Y: Physiologic limitations during daily life activities in COPD patients. Respir Med 2010;104:1152-1160.
Casaburi R: Strategies to reduce dynamic hyperinflation in chronic obstructive pulmonary disease. Pneumonol Alergol Pol 2009;77: 192-195.

7 Puente-Maestu L, Stringer WW: Hyperinflation and its management in COPD. Int J Chron Obstruct Pulmon Dis 2006;1:381-400.

8 Gelb AF, Fraser C, Zamel N: Lack of protective effect of tiotropium vs induced dynamic hyperinflation in moderate COPD. Respir Med 2011;105:755-760. 